\title{
Study Reveals Fuel Injection Timing Impact on Particle Number Emissions
}

Start of injection can improve environmental performance of fuel-efficient gasoline direct injection engines.

In an ongoing quest to meet ever-more-rigorous fuel economy and emissions requirements, vehicle manufacturers are increasingly turning to gasoline direct injection (GDI) coupled with turbocharging as a cost-effective option for improving the efficiency and performance of gasoline engines. While GDI engines are expected to account for $60 \%$ of the U.S. market by 2016, and the technology offers fuel economy and $\mathrm{CO}_{2}$ reduction benefits, it can have higher particulate matter (PM) mass and particle number (PN) emissions than conventional port fuel injection equipment.

National Renewable Energy Laboratory (NREL) researchers studied GDI engine operating parameters' effect on PN emissions to pinpoint areas for improvements aimed at reducing emissions and enhancing market viability. Their research examined start of injection (SOI), spark timing, fuel injection pressure, cam phasing, and fuel-air ratios in both hot and cold engine conditions. The NREL team found that SOI has the greatest impact on PN emissions. When SOl occurs too early, liquid fuel may impinge on the piston bowl, resulting in fuel that may not be totally vaporized and well mixed with intake air at the start of combustion, which leads to increased PN emissions. The NREL study shows impingement can be averted with calibration of SOI later than 270 degrees before the piston reaches top dead center in the cylinder. Additionally, a multiple-injection strategy can reduce fuel impingement during highload operation.

High fuel injection pressure is another key strategy in controlling PN emissions, as long as it does not diminish fuel economy or create pump durability concerns. Although optimization of spark timing, exhaust cam phasing, and intake cam phasing can cut PN emissions, changes to these parameters can also decrease engine efficiency and generate other polluting emissions.

Technical Contact: Brad Zigler, brad.zigler@nrel.gov

Reference: He, X.; Ratcliff, M.A.; Zigler, B.T. (2012). "Effects of Gasoline Direct Injection Engine Operating Parameters on Particle Number Emissions." Energy \& Fuels 26 (4); 2014-2027; DOI: 10.1021/ef201917p.

\section{Key Research Results}

\section{Achievement}

NREL researchers studied the key factors that contribute to PN emissions from GDI engines and found that fuel injection timing and fuel injection pressure are significant factors.

\section{Key Result}

The NREL team observed that by avoiding fuel impingement on the piston bowl, they could achieve more than an order-of-magnitude reduction in PN emissions.

\section{Potential Impact}

As GDI engines reach meaningful market penetration, strategies for reducing PN emissions will be important in meeting strict emissions requirements and accelerating consumer adoption.
NREL is a national laboratory of the U.S. Department of Energy, Office of Energy Efficiency and Renewable Energy, operated by the Alliance for Sustainable Energy, LLC.

15013 Denver West Parkway Golden, CO 80401 303-275-3000 | www.nrel.gov 